\title{
A DECADE OF SPACEBORNE OBSERVATIONS OF THE ARCTIC ATMOSPHERE Novel Insights from NASA's AIRS Instrument
}

\author{
by Abhay Devasthale, Joseph Sedlar, Brian H. Kahn, Michael TJernström, Eric J. Fetzer, \\ Baijun tian, Joao Teixeira, and Thomas S. Pagano
}

The Atmospheric Infrared Sounder (AIRS) is making important contributions to improved understanding of the vertical structure of the lower Arctic troposphere and its interactions with declining sea ice.

A rctic sea ice is diminishing rapidly, and its annual extent minima reached record low values twice during the last decade (Stroeve et al. 2008; Devasthale et al. 2013). The declining sea ice in a warming world has large environmental and socioeconomic implications. Therefore, it is imperative that global climate models simulate the current changes in the Arctic climate system as accurately as possible. This would help not only to carry out realistic assessments of future changes in the Arctic climate system but also to design relevant environmental and economic policies for decades to come. However, present models have great difficulty in describing the current development and consequently, future climate projections from climate models still exhibit large uncertainties over the Arctic despite considerable progress over the last few decades (IPCC 2013). One of the main sources of uncertainties is an inadequate representation of key atmospheric processes and their coupling to the surface (Döscher et al. 2014; Vihma et al. 2014). This in turn hinges on poor understanding of the vertical structure of the Arctic atmosphere. Many prevalent phenomena in the Arctic, such as temperature and humidity inversions, large-scale atmospheric transport of moisture and heat, and their interactions with the surface, necessitate a well-resolved vertical structure of the lower troposphere. The lack of observations of essential climate variables is an underlying problem as well (Vihma et al. 2014).

In situ measurements have helped to alleviate uncertainties by improving our understanding of the Arctic atmosphere. The long-term, dedicated measurements of basic meteorological variables from some of the sites-such as Barrow, Alaska; Eureka, Canada; and Ny Ålesund, Norway-have been used in many studies to characterize the Arctic atmosphere (Kahl 1990; Kahl et al. 1992a,b, 1996; Persson et al. 2002; Serreze et al. 1992; Garrett and Zhao 2006; Lubin and Vogelmann 2006; Shupe et al. 2008, 2011; Vihma et al. 2011; Zhang and Seidel 2011; Zhang et al. 2011; Persson 2012; Nygård et al. 2014; Qiu et al. 2015). These measurements are often used for satellite sensor validation and also provide important constraints for reanalysis systems (Dee et al. 2011). Within the central Arctic, detailed measurement campaigns, such as the Surface Heat Budget of the Arctic Ocean (SHEBA; Uttal et al. 
2002) and the Arctic Summer Cloud Ocean Study (ASCOS; Tjernström et al. 2014), have provided valuable insights into the processes that regulate air-sea ice interactions in the lowermost troposphere.

Despite their pivotal role, the in situ measurements are sparsely available, inhomogeneously distributed, and often initiated in the vicinity of marginal ice zones (MIZ). Detailed measurement campaigns in the central Arctic are even sparser and are biased toward summer conditions. Characterizing the lower troposphere over the central Arctic, where the boundary layer can be quite different from the MIZ, over the whole annual cycle has remained largely elusive. Since its launch over a decade ago, in May of 2002, observations from the hyperspectral Atmospheric Infrared Sounder (AIRS) on board the National Aeronautics and Space Administration (NASA)'s Aqua satellite (Chahine et al. 2006) are contributing to closing this gap by providing the data necessary to improve our understanding of the vertical structure of the interior Arctic atmosphere.

The Arctic lower troposphere directly interacts with sea ice, and its short-term variability in this portion of the atmosphere is profiled by the AIRS instrument owing to its hyperspectral sounding capability. A growing number of studies are exploiting AIRS data to investigate the thermodynamic structure of the Arctic atmosphere, with applications ranging from understanding processes to deriving climatologies (Kay et al. 2008; Pavelsky et al. 2011; Devasthale et al. 2010, 2011, 2012, 2013; Sedlar and Devasthale 2012; Boisvert et al. 2015; Boisvert and Stroeve 2015)_all of which are also useful to test and improve parameterizations in climate models.

AfFiliationS: DeVASTHALE-Atmospheric Remote Sensing Unit, Research and Development, Swedish Meteorological and Hydrological Institute, Norrköping, Sweden; SedLAR AND TJERnSTRömDepartment of Meteorology, and Bolin Centre for Climate Research, Stockholm University, Stockholm, Sweden; Kahn, FetZer, Tian, Teixeira, And Pagano-Jet Propulsion Laboratory, California Institute of Technology, Pasadena, California

CORRESPONDING AUTHOR: Abhay Devasthale, Atmospheric Remote Sensing Unit, Research and Development, Swedish Meteorological and Hydrological Institute, Folkborgsvägen 17, 60176 Norrköping, Sweden

E-mail: abhay.devasthale@smhi.se

The abstract for this article can be found in this issue, following the table of contents.

DOI:10.II75/BAMS-D-14-00202.I

A supplement to this article is available online (I0.II75/BAMS-D-14-00202.2)

In final form 2 February 2016

(C2016 American Meteorological Society
As AIRS data now span more than a decade, we demonstrate five science topics that have benefitted greatly from AIRS observations: 1) Climatologies of temperature and water vapor inversions: These are ubiquitous features of the Arctic atmosphere and affect energy exchanges near the surface. 2) Influence of free-tropospheric moisture transport on surface temperatures: Recent studies argue that this process drives the atmospheric preconditioning that eventually accelerates summer sea ice melt. 3) Variability of liquid clouds, especially in relation to sea ice concentration: It is expected that new ice-free ocean areas will support increases in low clouds. 4) Trends in temperature and water vapor vertical structure during the last decade. 5) Joint retrievals of temperature and water vapor in studying the thermodynamic state of the atmosphere during record minimum sea ice extent years.

\section{AIRS DATASET USED IN THE PRESENT} STUDY. To demonstrate the science capability of AIRS over the Arctic, we analyzed data from the Aqua AIRS Level 3 Daily Standard Physical Retrieval (AIRX3STD) product, which provides twice daily retrievals of temperature and humidity, among other parameters, globally at $1^{\circ} \times 1^{\circ}$ resolution. For studying inversions, only clear-sky retrievals were used. Figures ES1-ES5 in the online supplemental material (http://dx.doi.org//0.II75/BAMS-D-14-00202.2) show step-by-step processing and subsampling of AIRS data.

AIRS data products are being continually validated throughout the course of the mission. For example, the efforts to validate the most recent version 6 retrievals, which are used in the present study, are summarized in Dang et al. (2012). Since the focus of the present study is on the Arctic, we investigated whether AIRS temperature and humidity retrievals agree with in situ measurements specifically in the Arctic. For this purpose we used soundings from Barrow for the 12-yr period of 2003-14. The details of this comparison are presented in Figs. ES6 and ES7 in the online supplemental material. It was found that AIRS provides a reasonably accurate description of the thermodynamic state of the Arctic atmosphere. In brief, the correlations for temperature retrievals are better than 0.96 with $\mathrm{rms}$ values around $1.2 \mathrm{~K}$ (in the middle troposphere) to about $3.0 \mathrm{~K}$ (near surface), while corresponding values for humidity retrievals are around 0.87 for correlation and $0.02-0.60 \mathrm{~g} \mathrm{~kg}^{-1}$ for rms errors.

ATMOSPHERIC INVERSIONS. The most ubiquitous phenomenon within the Arctic lower troposphere is the temperature inversion (e.g., Wexler 
1936; Vowinkel and Orvig 1970; Kahl 1990; Kahl et al. 1992a,b; Serreze et al. 1992; Zhang and Seidel 2011; Zhang et al. 2011). Boundary layer temperature inversions dominate all seasons but display a strong seasonality (e.g., Tjernström and Graversen 2009). During cloud-free winter conditions, strong surface inversions form due to longwave surface cooling, while low clouds tend to generate elevated cloud-top inversions due longwave cloud-top cooling (e.g., Tjernström et al. 2004; Tjernström and Graversen 2009; Sedlar and Tjernström 2009; Devasthale et al. 2010; Sedlar et al. 2012). These two states occur about half the time each and the change between them is governed by the larger-scale atmospheric circulation (e.g., Morrison et al. 2012). In summer, low clouds dominate the central Arctic and hence almost all inversions are elevated, located close to the cloud tops (Tjernström et al. 2012). Humidity inversions are also a common occurrence over the Arctic (Tjernström et al. 2004; Devasthale et al. 2011; Sedlar et al. 2012; Nygård et al. 2014). Although temperature and humidity inversions have been widely studied in the last few decades based on the data available from in situ measurements (Kahl 1990; Kahl et al. 1992a,b; Serreze et al. 1992; Tjernström and Graversen 2009; Zhang and Seidel 2011; Zhang et al. 2011) and, to some extent, using retrievals from satellite sensors in boreal winter (Liu et al. 2006), Arctic-wide mapping of inversion characteristics and their seasonality (Fig. 1) has been possible only after the launch of AIRS on board the Aqua satellite (Devasthale et al. 2010, 2011; Pavelsky et al. 2011). This is undoubtedly the most valuable contribution of AIRS in increasing our understanding of the vertical structure of the Arctic atmosphere. The mere fact that inversions can be resolved at a daily scale, covering nearly the entire Arctic, opens up a number of possibilities to carry out process-based sensitivity studies. Mapping inversion characteristics reveals the complex nature of seasonal and spatial heterogeneity in Arctic-wide inversion structures (Fig. 1). It is evident that the Canadian archipelago and surrounding ocean show consistently high median temperature inversion strengths during winter [December-February (DJF)], while the Pacific sector of the Arctic dominates the inversion statistics in summer. Among all seasons, water vapor inversion strength is highest during summer, consistent with the radiosounding analysis reported in Devasthale et al. (2011) and Nygård et al. (2014); this also occurs in the Pacific sector, coinciding with large temperature inversion strength, suggesting the increased influence of long-range transport of heat and moisture from the Pacific. As AIRS provides reasonably accurate retrievals of thermodynamic variables even within partly cloudy conditions (Wong et al. 2015), the observations help facilitate the investigation of inversion characteristics as a function of cloud fraction. As demonstrated in the online supplement (Figs. ES8-ES11), the spatial patterns of temperature and humidity inversion frequency and strength are consistent up to $50 \%$ cloud cover.

The impacts of temperature inversion structures in the Arctic are multifaceted measurements (Kahl 1990; Kahl et al. 1992a,b; Serreze et al. 1992; Tjernström and Graversen 2009; Zhang et al. 2011). Surface inversions determine the direction and magnitude of turbulent fluxes in the atmospheric boundary layer (e.g., Tjernström et al. 2005), influencing surface skin temperatures, and interact with low clouds; inversions form at the top of the cloud by cloud-top cooling but at the same time limit the exchange between the cloud layer and the free troposphere. Recent in situ observations from the central and pan-Arctic however demonstrate a rather complex interaction between thermodynamic structure and low-level clouds (Sedlar and Tjernström 2009; Sedlar et al. 2012; Shupe et al. 2013; Sedlar 2014; Sotiropoulou et al. 2014). Most frequently, cloud tops are found to penetrate into the thermally stable inversion layer in the central Arctic and persist above the inversion base rather than being capped by it (Sedlar and Tjernström 2009; Sedlar et al. 2012). This observed structure indicates the potential importance of horizontal advection into the high-latitude Arctic as a means of modifying cloud-top cooling from radiative divergence (e.g., Sedlar 2014). These cloud layers are often decoupled from the surface by secondary subcloud inversions (Sotiropoulou et al. 2014). Furthermore, central Arctic studies, including one examining AIRS thermodynamic profiles, have demonstrated that temperature inversions are often accompanied by humidity inversions (Devasthale et al. 2011; Sedlar et al. 2012; Nygård et al. 2014); such a feature is not frequently observed above the marine boundary layer in the subtropics (Yue et al. 2011). Specific humidity inversions may be one explanation why cloud tops often penetrate-and persist within-stable inversion layers (Sedlar et al. 2012).

From a climate perspective, temperature and humidity inversions play an important role. For example, the strength of a surface inversion has been suggested to enhance Arctic amplification, by suppressing the cooling caused by longwave radiation escaping to space during the winter half of the year (Bintanja et al. 2011). Any future changes in the climatological characteristics of inversions, or in 
DJF

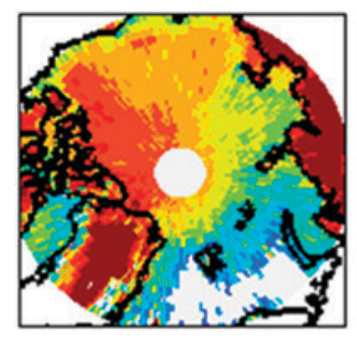

DJF

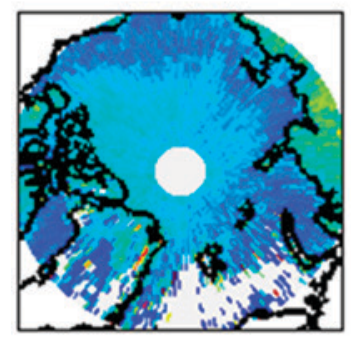

MAM

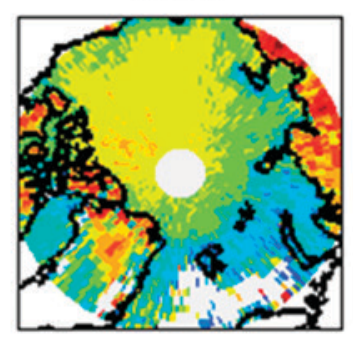

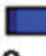

JJA

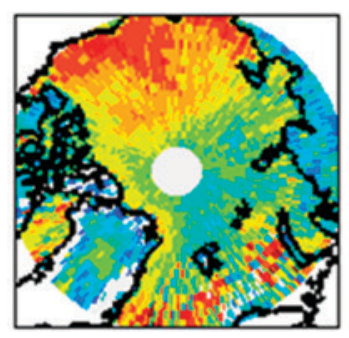

5

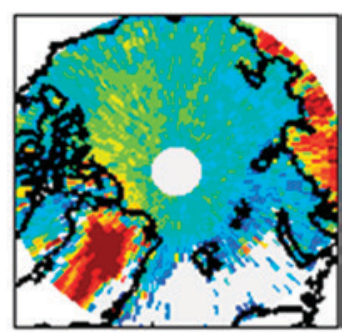

10 [K]

JJA
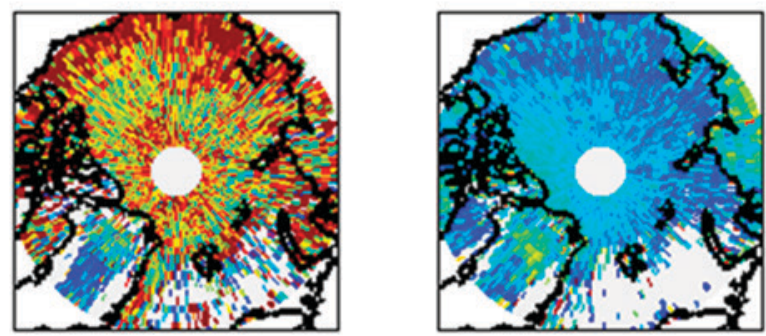

0.0

0.05

0.1

0.15

$0.2[\mathrm{~g} / \mathrm{kg}]$

FIG. I. Seasonal maps [Dec-Feb (DJF); Mar-May (MAM); Jun-Aug (JJA); Sep-Nov (SON)] showing (top) median temperature and (bottom) water vapor inversion strengths based on II years of AIRS retrievals (Oct 2002-Sep 2013). Both surface-based and elevated inversions are included in the analysis. Only clear-sky AIRS retrievals are analyzed here. However, changes in these quantities with cloud fraction are shown in Figs. ES8-ESII in the online supplemental material. The regions with poor statistical sampling are masked with white color. Inversions are detected as follows. For a given temperature profile from the surface up to $300 \mathrm{hPa}$, surface temperature values are differenced with air temperatures working upward. If no inversion is detected, then the next vertical level is differenced and the procedure is repeated successively for all vertical layers up to $300 \mathrm{hPa}$.

the climatological thermodynamic structure of the atmosphere above the inversions, may further impact this positive feedback. Coincident temperature and moisture increases will also impact both the thermal emissivity and emission temperature of the Arctic atmosphere. Anomalous temperature and moisture advection have been found to impact the clear-sky atmospheric longwave greenhouse effect, resulting in direct responses in surface temperatures (e.g., Sedlar and Devasthale 2012). The role of advection and formation of temperature and moisture inversions on longwave radiative forcing is even more pronounced indirectly via their relation to cloud formation. Temperature inversions further impact the air quality (Law et al. 2014), especially in the inhabited, continental parts of the Arctic, worsening it by preventing the dilution of pollutants by vertical mixing and thus accumulating high concentrations of pollutants in the boundary layer. However, over the Arctic Ocean, the stably stratified atmosphere may limit the vertical mixing to the surface of socalled Arctic haze, formed by the isentropic transport of anthropogenic pollutants from the midlatitudes into the Arctic and photochemical reactions at polar sunrise (Law et al. 2014).

As climate models are chronically biased when simulating inversion characteristics in the Arctic, including frequency and strength (Boé et al. 2009; Medeiros et al. 2011; Zhang et al. 2011; Brunke et al. 2015), the characteristics of inversions derived from AIRS help to diagnose atmospheric vertical structure while also providing a sanity check for climate models. One such process affecting the lower-troposphere stability is the transport of heat and moisture into the Arctic, the wider impact of which is studied with AIRS as demonstrated in the next section.

\section{IMPACT OF MOISTURE TRANSPORT INTO} THE ARCTIC. As Arctic sea ice thins (Kwok and Rothrock 2009; Serreze and Barry 2011; Vihma 2014), 
there is growing evidence that so-called preconditioning of the Arctic during winter and spring plays an increasing role, making sea ice melt vulnerable to short-term atmospheric variability during the following summer (Maslanik et al. 2007; Kay and Gettelman 2009; Graversen et al. 2011; Devasthale et al. 2013; Kapsch et al. 2013). The preconditioning could manifest itself in a number of ways, for example (and not limited to), sustained warming periods during winter or spring; favorable wind patterns for sea ice transport out of the Arctic; strong and episodic heat transport; and changes to the cloud cover and their radiative impact. One such preconditioning mechanism, potentially related to those listed above, is an anomalously large transport of moisture and heat into the Arctic, a critical component of the accelerated sea ice melt during summer 2007 that eventually led to a record low ice extent (Graversen et al. 2011; Sedlar and Devasthale 2012; Kapsch et al. 2013). The 11-yr (2012-13) AIRS data record now enables analysis of moisture and heat transport impacts on surface temperatures over the Arctic. To demonstrate this, we first identified moisture transport events using European Centre for Medium-Range Weather Forecasts (ECMWF) interim reanalysis (ERA-Interim) data. We then required the moisture flux into the Arctic across $70^{\circ} \mathrm{N}$ to exceed its 90th percentile value. Furthermore, we required it to be present for at least 24 hours, allowing moisture to extend over the central Arctic ice pack. The advection was also subdivided into four longitudinal sectors that were based on Woods et al. (2013), including the Atlantic Ocean (AT, bounded by $30^{\circ} \mathrm{W}-25^{\circ} \mathrm{E}$ ), the Barents and Kara Seas (BK, $25^{\circ}-90^{\circ} \mathrm{E}$ ), the Pacific Ocean (PC, $\left.145^{\circ} \mathrm{E}-135^{\circ} \mathrm{W}\right)$, and the Labrador Sea (LB, $\left.90^{\circ}-30^{\circ} \mathrm{W}\right)$. The transport events were then matched to AIRS skin temperature retrievals to evaluate their impact on surface temperatures.

The PC and LB sectors dominate the total number of large moisture transport events during summer months, while the AT sector is largely responsible for the transport across $70^{\circ} \mathrm{N}$ during winter months, as the winter storms reach the northernmost latitudes in the North Atlantic. Figure 2 shows the magnitude and extent of surface warming that these events generated in the Arctic. Anomalies are shown with respect to the seasonal AIRS surface temperature climatological average. Although the occurrence of transport events is higher during summer than in winter (see Fig. ES12 in the online supplemental material), the magnitude of the surface warming is more than double in winter, reaching and often exceeding $5 \mathrm{~K}$, even when averaged over a large number of events. This periodic winter warming could potentially hinder the recovery of sea ice during colder months, resulting in thinner sea ice that is more sensitive to short-term changes in Arctic weather events, or precondition the ice for rapid melt by an earlier melt onset. Apart from displaying a strong seasonal character, the magnitude and extent of surface warming substantially differ across the sectors with season. For example, while the warming is more spatially widespread when the moisture transport occurs within the AT sector during winter months, its magnitude is the highest when the transport occurs within the PC sector. In the summer months, the relative contributions of the AT and PC sectors to the extent and magnitude are reversed.

Process-oriented studies similar to this using AIRS data not only allow realistic quantification of the potential impact of moisture and heat transport into the Arctic but also form a basis for process-oriented evaluation of climate models.

\section{RESPONSE OF CLOUDINESS TO MELTING}

SEA ICE. Clouds often lead to a surface warming in the Arctic compared to clear conditions. This is due to a dominant longwave radiative effect in the presence of sea ice and snow at the surface. With a high surface albedo, the presence of clouds increase the net surface longwave radiation much more than the net shortwave is diminished (Walsh and Chapman 1998; Shupe and Intrieri 2004; Kay and L'Ecuyer 2013). A clearer understanding of the cloud response, especially liquid-phase clouds, which greatly impact the longwave emissivity, to sea ice melt is crucial. Previous studies using space-based imagers suggest that there indeed exists a strong negative correlation between cloud cover and sea ice concentration (Liu et al. 2012; Liu and Key 2014).

Owing to its high spectral resolution, AIRS is capable of providing estimates of cloud thermodynamic phase; this information will provide insights into how cloudiness responds to decreasing sea ice concentrations. To demonstrate, the most recent version 6 monthly mean cloud properties (Kahn et al. 2014) are collocated with retrievals of sea ice concentrations from the European Organisation for the Exploitation of Meteorological Satellites (EUMETSAT)'s Ocean and Sea Ice Satellite Application Facility (OSI SAF; www.osi-saf.org/). Clouds classified as liquid phase or unknown phase are considered in the analysis. The latter category of clouds is found to frequently contain supercooled liquid water or mixed-phase structure (Jin and Nasiri 2014; Lubin et al. 2015). Liquid cloud fractions and sea ice concentrations clearly show negative correlations during the melting season over areas where sea ice melt has been accelerated during the last 

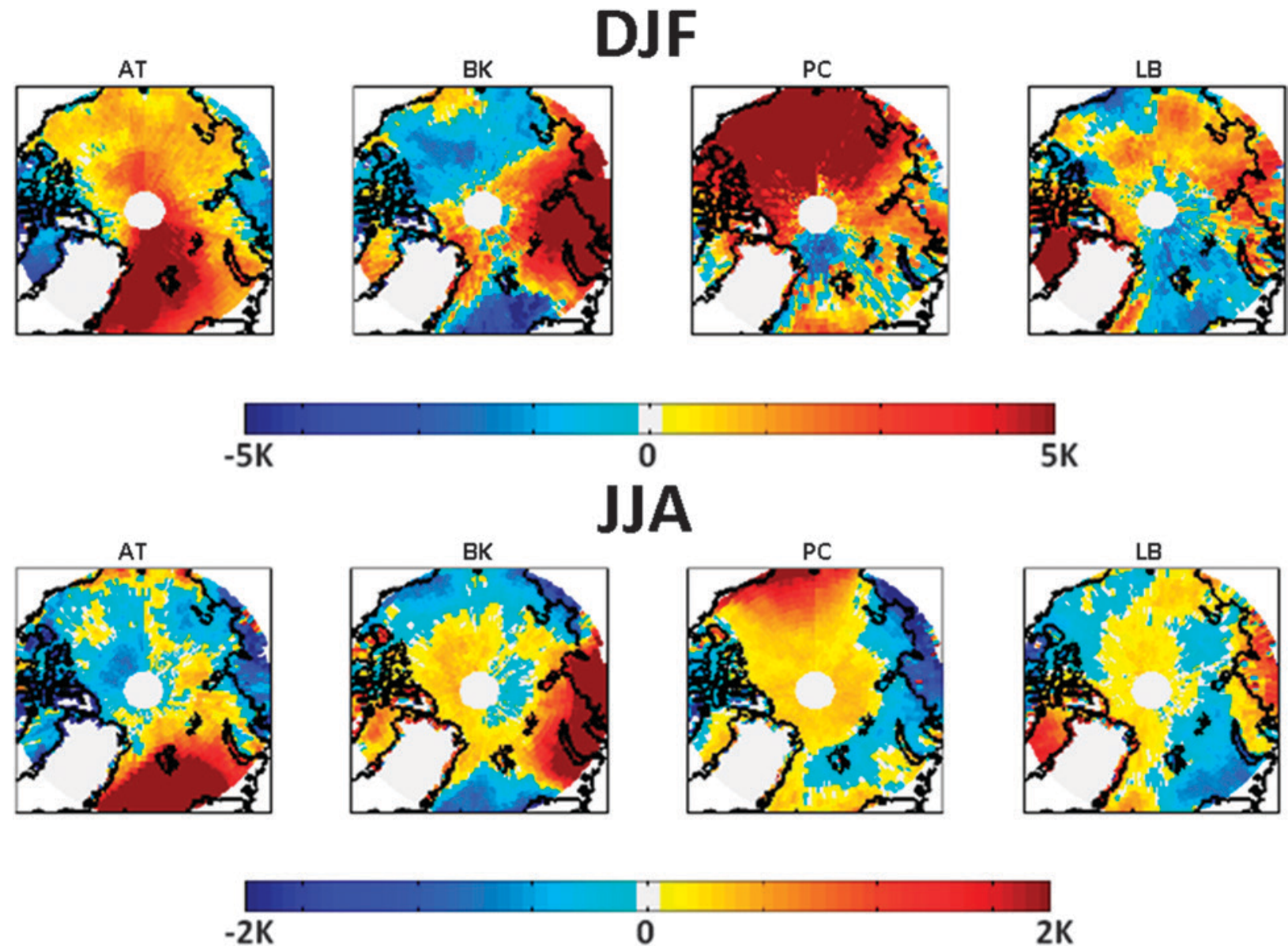

FIG. 2. Surface temperature anomalies $(K)$ with respect to seasonal means, averaged over events when the northward moisture transport across $70^{\circ} \mathrm{N}$ into the Arctic from four sectors (see text for details) exceeds its corresponding 90 th percentile value and persists for at least 24 hours.

decade (Fig. 3). A closer look at different months reveals that cloudiness has increased in the Atlantic, Barents Sea, and Kara Sea sectors of the Arctic in June and July (see Fig. ES13 in the online supplemental material). These regions are among the first to experience sea ice melt at the beginning of the summer season. The MIZ in these sectors is more likely to have thin first-year ice exposed to relatively warm upper-ocean water from the Atlantic. From August until October, an increase in cloud fraction in the Pacific sector of the Arctic is visible. Most of the Arctic displays negative correlations between cloudiness and sea ice extent; however, the statistical significance is not high $(\sim 80 \%)$, possibly due to a relatively short data record combined with a large interannual variability.

ZONAL TRENDS IN TEMPERATURE AND HUMIDITY. A major advantage of a satellite sounder is the ability to observe the temporal evolution of the three-dimensional atmosphere. In this context, trend quantifications of temperature and specific humidity, previously limited to reanalysis data or model simulations, are now investigated using AIRS observations (Boisvert and Stroeve 2015). Zonal averages of monthly temperature and water vapor trends over the AIRS observational period are examined in Figs. 4 and 5.

There is consistency and correlation between both temperature and humidity trends (Figs. 4 and 5). This is in part due to the strong dependency of water vapor on temperature because of the Clausius-Clapeyron relationship. Coherent patterns in the tropospheric trends of both temperature and humidity emerge within zonal averages during March, September, and October. March and September indicate vertically extensive warming and moistening over the sea ice poleward of $70^{\circ} \mathrm{N}$. A warmer and moister spring may be an important factor in the fate of sea ice during the subsequent summer and autumn (Graversen et al. 2011; Sedlar and Devasthale 2012; Kapsch et al. 2013; 

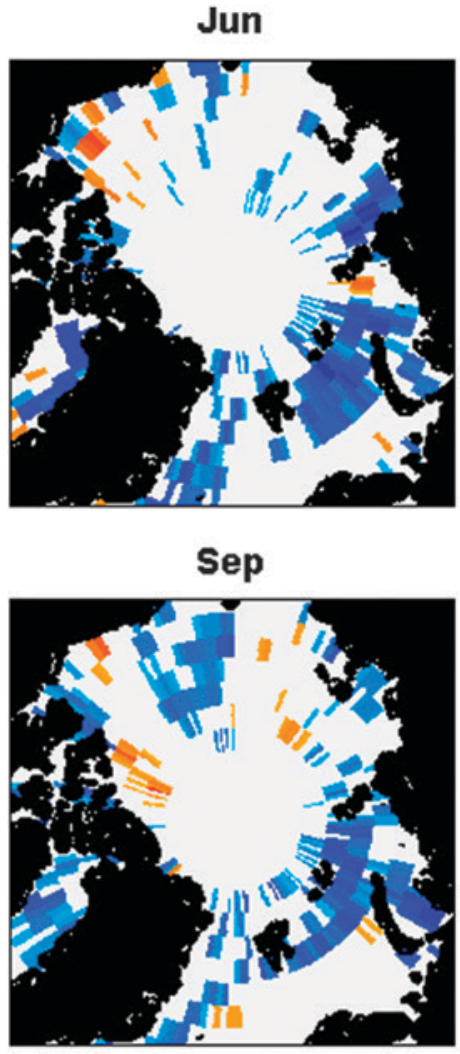

Jul

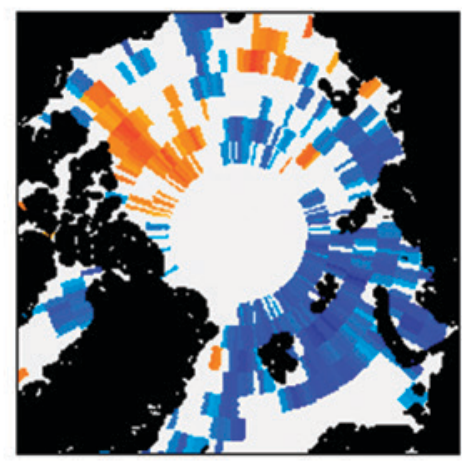

Oct

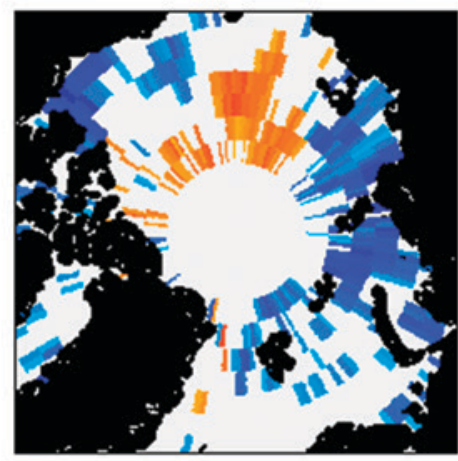

Aug

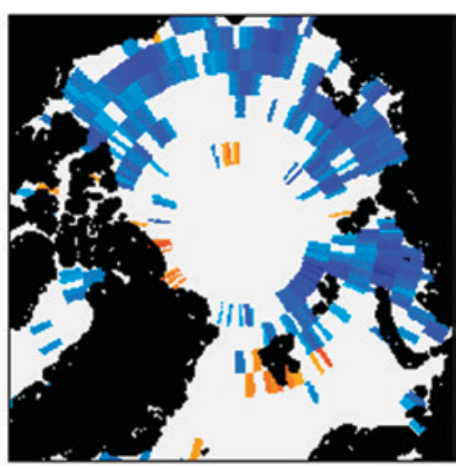

Nov

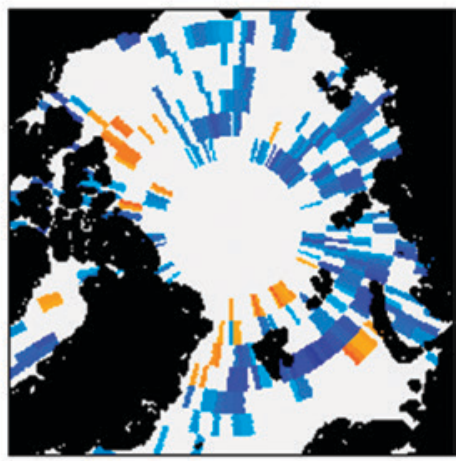

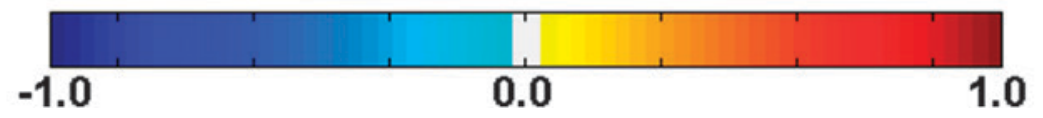

FIG. 3. Correlation of sea ice concentration with liquid-phase cloud fraction based on the AIRS data record. AIRS version 6 monthly mean cloud retrievals and OSI SAF sea ice concentration data are used for analysis. Only those correlations significant at the $\mathbf{8 0} \%$ confidence level are shown.

Devasthale et al. 2013). This may be a key mechanism in the preconditioning of sea ice through enhanced atmospheric greenhouse warming from increased water vapor, more clouds, or both. During September, the central Arctic Ocean sea ice has reached its minimum and melting has ceased (e.g., Mortin et al. 2014). A strong September warming trend supports a large, positive trend in water vapor primarily below about $700 \mathrm{hPa}$ (Fig. 5). Interestingly, the positive trends are short lived and are largely absent or negative by October. This is an intriguing result because climate model simulations show significant positive trends throughout the lower troposphere during the full autumn season (Screen et al. 2014) once excessive heat taken up the upper ocean is released back into the atmosphere to form first-year ice.

Trends in temperature are generally positive and larger than about $0.1 \mathrm{~K} \mathrm{yr}^{-1}$ in the lowest portion of the troposphere during late autumn and winter (Fig. 4). These trends are confined within the $70^{\circ}-80^{\circ} \mathrm{N}$ latitude band and suggest a response in the lower-tropospheric temperature to the previous years' ice melt. This latitude band tends to be where the majority of ice melt and first year ice formation occurs (e.g., Maslanik et al. 2011). The lower troposphere also shows increased moisture in the same latitude band during late autumn and winter (Fig. 5), which may suggest a positive feedback on lower-tropospheric warming through an enhanced atmospheric greenhouse forcing.

The temperature trends are rather weak during summer over latitudes where sea ice is present. The primarily reason is that energy is consumed in latent heat processes at the surface (melting of sea ice and snow) rather than in sensible heating (Fig. 4). Humidity trends, however, tend to be positive and large farther south nearer to the open ocean and marginal ice zones, and also nearer to the pan-Arctic landmasses. During June and July, positive trends in water vapor poleward of $75^{\circ} \mathrm{N}$ are also observed but 

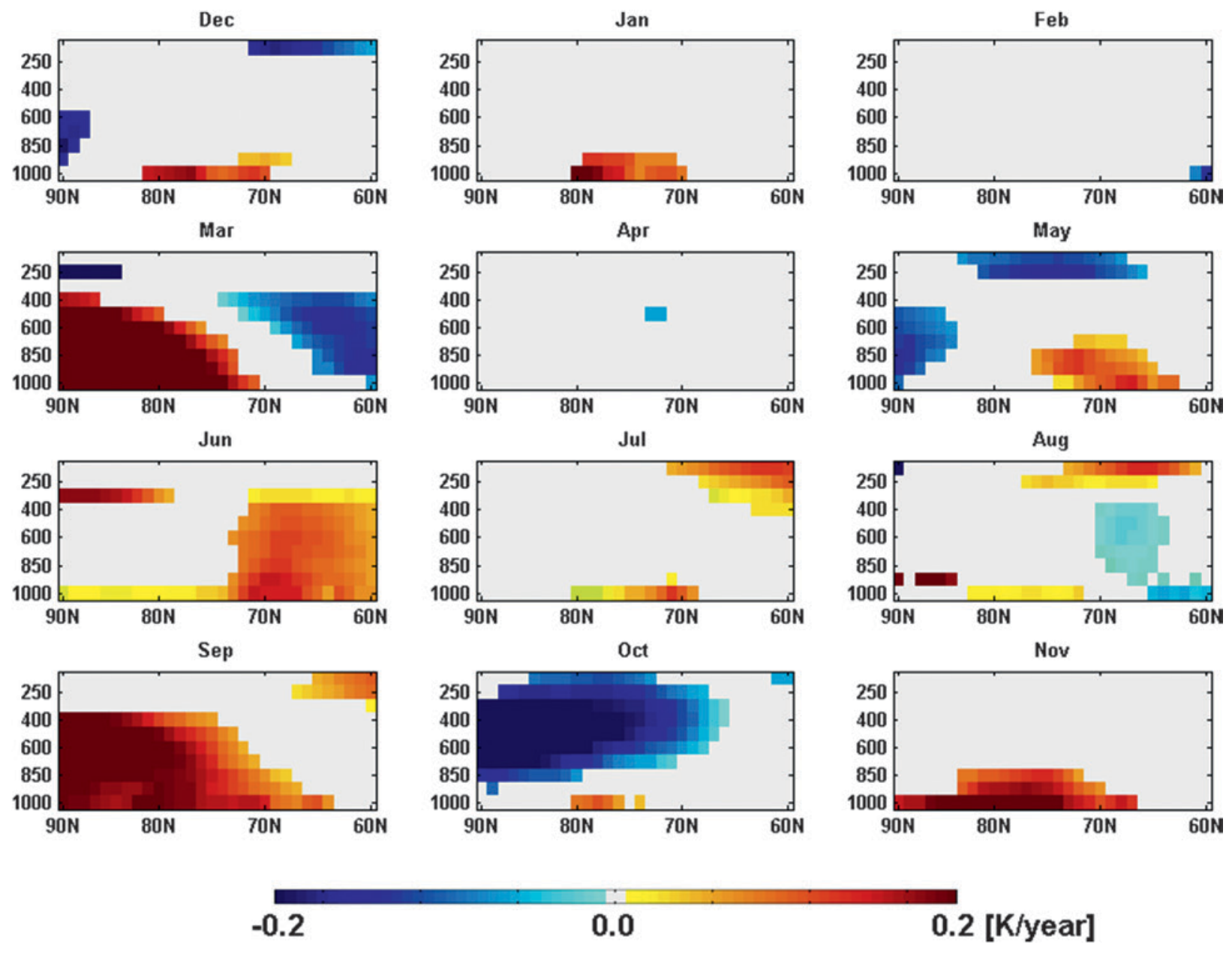

FIG. 4. Monthly zonal temperature trends over the Arctic. Only those trends where the changes in temperatures over a decade exceed one standard deviation are shown.

are extended above the surface (Fig. 5). Within this region and time period, there is no corresponding correlation with temperature trends, which could have implications for cloud formation (see Fig. ES6). The dominant temperature trends observed during March, September, and October are robust even when excluding the record minimum sea ice years of 2007 and 2012 (not shown).

\section{CHANGES IN MOIST STATIC ENERGY} DURING RECORD MINIMUM SEA ICE

YEARS. The simultaneous profiles of temperature, humidity, and geopotential height from AIRS are combined to estimate moist static energy (MSE). Estimates of MSE are useful for understanding different contributions to atmospheric preconditioning in recent years when record minima sea ice extents were observed (e.g., 2007 and 2012). MSE is a combination of internal $(T)$, potential $(z)$, and latent $(q)$ energy, and is conserved during adiabatic motions. The mass-weighted vertical integral of MSE is estimated as

$$
\mathrm{MSE}=c_{p} \int_{p_{1000}}^{p_{100}} T \frac{d p}{g}+g \int_{p_{1000}}^{p_{100}} z \frac{d p}{g}+L_{v} \int_{p_{1000}}^{p_{100}} q \frac{d p}{g},
$$

where $c_{p}$ is the heat capacity of dry air, $g$ is the acceleration of gravity, and $L_{\mathrm{u}}$ is the latent heat of vaporization; MSE is integrated across the full AIRS atmospheric column from 1000 to $100 \mathrm{hPa}$. Devasthale et al. (2013) found distinct anomalies in the winter and spring meridional MSE anomalies between $65^{\circ}$ and $85^{\circ} \mathrm{N}$ for the recent record sea ice minima years of 2007 and 2012. These MSE anomalies showed striking meridionally averaged coherence with negative anomalies from the North American and Greenland sectors and positive anomalies over the North Atlantic and Eurasia and Siberia. Devasthale et al. (2013) argue that areas with a positive MSE anomaly were impacted by atmospheric 

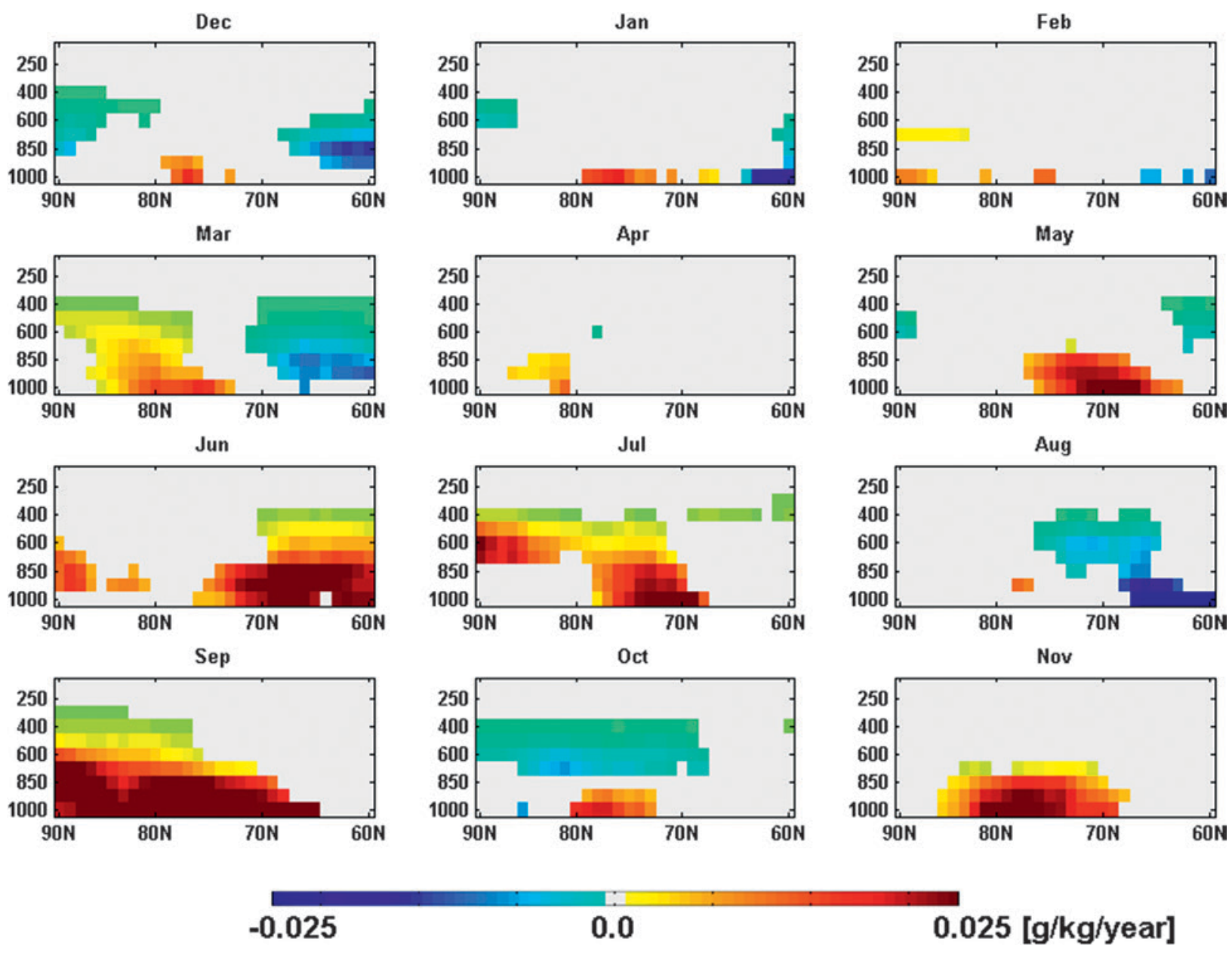

FIG. 5. Monthly zonal water vapor trends over the Arctic.

preconditioning of snow and sea ice during winter and spring. These are areas where enhanced energy from the atmosphere contributed to a modification of surface temperatures and likely inhibited sea ice growth (Graversen et al. 2011; Sedlar and Devasthale 2012).

To corroborate these results, the monthly vertically integrated MSE anomalies are estimated for 2007 and 2012 and their spatial distributions are shown in Fig. 6. The spatial structure of the monthly anomalies during March and April is strikingly similar. A positive anomaly in MSE emerges across the North Atlantic Ocean and the Barents and Kara Seas that transitions toward negative anomalous values as spring progresses. At the same time, positive anomalies emerge over eastern Siberia and the North American continent, affecting the Laptev, East Siberian, Chukchi, and Beaufort Seas, and the Canadian archipelago (Fig. 6).

By summer [June-August (JJA)], the spatial coherency in anomalous MSE between 2007 and 2012 decreases, and instead the strongest positive anomalies are found over the regions where the largest ice-free areas were observed in September of each respective year. Significant positive anomalies are observed over the Pacific Arctic during summer, corresponding to strong high pressure anomalies and atmospheric heat and moisture transport observed over the western portion of this region during 2007 (Schweiger et al. 2008; Kay et al. 2008). The summer MSE anomalies of 2012 were generally not as pronounced as in 2007 . However, a number of preconditioning factors contributed to melting a substantial amount of ice in the North Atlantic Ocean and the Laptev and Beaufort Seas during 2012 (Devasthale et al. 2013). Surface warming during winter and spring, an Arctic sea ice regime transitioning toward a system that consists of a larger concentration of thinner first-year ice, and a declining trend in multiyear ice extent and thickness (e.g., Kwok et al. 2009; Maslanik et al. 2011) may have played important roles.

OUTLOOK. For more than a decade, AIRS has observed the Arctic gradually transitioning to a more vulnerable sea ice state (Maslanik et al. 2007, 

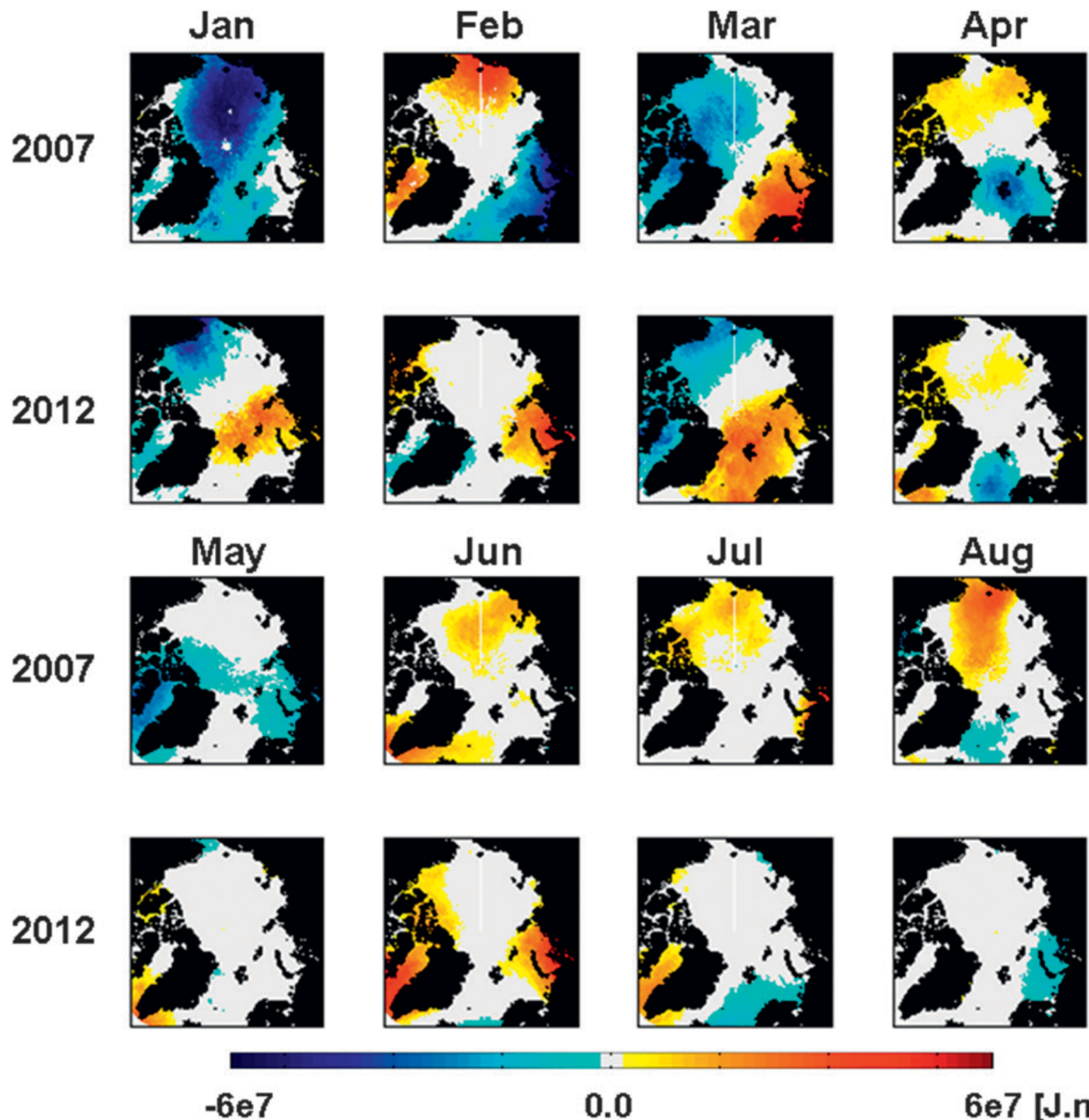

0.0

$6 \mathrm{e} 7\left[\mathrm{~J} . \mathrm{m}^{-2}\right]$

FIG. 6. Monthly mean anomalies of vertically integrated MSE derived using AIRS data for the two recent record minimum sea ice extent years of 2007 and 2012. Anomalies are with respect to MSE averaged for the II-yr period.

2011) and has provided new data to help us develop new insights into the vertical structure of the Arctic atmosphere, with further implications for evaluating and improving climate models in the Arctic.

In this new era of hyperspectral infrared remote sensing, the Infrared Atmospheric Sounding Interferometer (IASI) and Cross-track Infrared Sounder (CrIS) instruments are complementing the existing AIRS record. The synergy between these sensors could be exploited to investigate subtle diurnal cycles, or to infer subdaily variability in atmospheric transport. The synergy with other instruments flying on board the A-Train convoy of satellites has also not yet been fully maximized. The availability of highspatial-resolution $(\sim 1 \mathrm{~km})$ visible, near-infrared, and midinfrared imagery from the Moderate Resolution Imaging Spectroradiometer (MODIS) instrument collocated with AIRS on board the Earth Observing System (EOS) Aqua satellite not only provides a complementary set of geophysical variables to AIRS, but also additional improvements in the spatial resolution of temperature and water vapor sounding 
will be obtained from efforts that leverage both instruments' observations into a singular geophysical retrieval. A similar opportunity is available with the CloudSat radar and the Cloud-Aerosol Lidar and Infrared Pathfinder Satellite Observations (CALIPSO) lidar, launched in 2006. These instruments are making unprecedented near-simultaneous measurements of atmospheric thermodynamic profiles, clouds, and aerosols that are coaligned in space and time. With every passing year, the AIRS data record becomes increasingly relevant for climate monitoring of the Arctic.

ACKNOWLEDGMENTS. AD gratefully acknowledges the Swedish National Space Board (SNSB) for supporting the ArcticClim and GlobRAD projects. BHK was supported by the NASA Science of Terra and Aqua program under Grant NNN13D455T. The authors would like to thank the AIRS Science Team for its contributions in preparing the AIRS data record.

\section{REFERENCES}

Bintanja, R., R. G. Graversen, and W. Hazeleger, 2011: Arctic winter warming amplified by the thermal inversion and consequent low infrared cooling to space. Nat. Geosci., 4, 758-761, doi:10.1038/ngeo1285.

Boé, J., A. Hall, and X. Qu, 2009: Current GCMs' unrealistic negative feedback in the Arctic. J. Climate, 22, 4682-4695, doi:10.1175/2009JCLI2885.1.

Boisvert, L. N., and J. C. Stroeve, 2015: The Arctic is becoming warmer and wetter as revealed by the Atmospheric Infrared Sounder. Geophys. Res. Lett., 42, 4439-4446, doi:10.1002/2015GL063775.

—, D. L. Wu, and C.-L. Shie, 2015: Increasing evaporation amounts seen in the Arctic between 2003 and 2013 from AIRS data. J. Geophys. Res. Atmos., 120, 6865-6881, doi:10.1002/2015JD023258.

Brunke, M. A., S. T. Stegall, and X. Zeng, 2015: A climatology of tropospheric humidity inversions in five reanalyses. Atmos. Res., 153, 165-187, doi:10.1016/j .atmosres.2014.08.005.

Chahine, M. T., and Coauthors, 2006: AIRS: Improving weather forecasting and providing new data on greenhouse gases. Bull. Amer. Meteor. Soc., 87, 911-926, doi:10.1175/BAMS-87-7-911.

Dang, H. V. T., B. Lambrigtsen, and E. Manning, Eds., 2012: AIRS/AMSU/HSB version 6 level 2 performance and test report. Version 1.2, Jet Propulsion Laboratory, California Institute of Technology, 197 pp. [Available online at http://disc.sci.gsfc.nasa.gov /AIRS/documentation/v6_docs/v6releasedocs-1 /V6_L2_Performance_and_Test_Report.pdf.]
Dee, D. P., and Coauthors, 2011: The ERA-Interim reanalysis: Configuration and performance of the data assimilation system. Quart. J. Roy. Meteor. Soc., 137, 553-597, doi:10.1002/qj.828.

Devasthale, A., U. Willén, K.-G. Karlsson, and C. G. Jones, 2010: Quantifying the clear-sky temperature inversion frequency and strength over the Arctic Ocean during summer and winter seasons from AIRS profiles. Atmos. Chem. Phys., 10, 5565-5572, doi:10.5194/acp-10-5565-2010.

_ , J. Sedlar, and M. Tjernström, 2011: Characteristics of water-vapour inversions observed over the Arctic by Atmospheric Infrared Sounder (AIRS) and radiosondes. Atmos. Chem. Phys., 11, 9813-9823, doi:10.5194/acp-11-9813-2011.

—, M. Tjernström, M. Caian, M. A. Thomas, B. H. Kahn, and E. J. Fetzer, 2012: Influence of the Arctic Oscillation on the vertical distribution of clouds as observed by the A-Train constellation of satellites. Atmos. Chem. Phys., 12, $10535-10544$, doi:10.5194 lacp-12-10535-2012.

— J. Jedlar, T. Koenigk, and E. J. Fetzer, 2013: The thermodynamic state of the Arctic atmosphere observed by AIRS: Comparisons during the record minimum sea ice extents of 2007 and 2012. Atmos. Chem. Phys., 13, 7441-7450, doi:10.5194 /acp-13-7441-2013.

Döscher, R., T. Vihma, and E. Maksimovich, 2014: Recent advances in understanding the Arctic climate system state and change from a sea ice perspective: A review. Atmos. Chem. Phys., 14, 13 571-13600, doi:10.5194/acp-14-13571-2014.

Garrett, T., and C. Zhao, 2006: Increased Arctic cloud longwave emissivity associated with pollution from mid-latitudes. Nature, 440, 787-789, doi:10.1038 /nature04636.

Graversen, R. G., T. Maurtisen, S. Drijfhout, M. Tjernström, and S. Mårtensson, 2011: Warm winds from the Pacific caused extensive Arctic sea-ice melt in summer 2007. Climate Dyn., 36, 2103-2112, doi:10.1007/s00382-010-0809-z.

IPCC, 2013: Climate Change 2013: The Physical Science Basis. Cambridge University Press, 1535 pp., doi:10.1017/СBO9781107415324.

Jin, H., and S. L. Nasiri, 2014: Evaluation of AIRS cloud-thermodynamic-phase determination with CALIPSO. J. Appl. Meteor. Climatol, 53, 1012-1027, doi:10.1175/JAMC-D-13-0137.1.

Kahl, J. D., 1990: Characteristics of the low-level temperature inversion along the Alaskan Arctic coast. Int. J. Climatol., 10, 537-548, doi:10.1002/joc.3370100509.

—, M. C. Serreze, and R. C. Schnell, 1992a: Tropospheric low-level temperature inversions in 
the Canadian Arctic. Atmos.-Ocean, 30, 511-529, doi:10.1080/07055900.1992.9649453.

_ , S. M. Skony, M. C. Serreze, S. Shiotani, and R. C. Schnell, 1992b: In situ meteorological sounding archives for Arctic studies. Bull. Amer. Meteor. Soc., 73, 1824-1830, doi:10.1175/1520-0477(1992)073<1824:IS MSAF $>2.0 . C O ; 2$.

—, D. A. Martinez, and N. A. Zaitseva, 1996: Longterm variability in the low-level inversion layer over the Arctic Ocean. Int. J. Climatol., 16, 1297-1313, doi:10.1002/(SICI)1097-0088(199611)16:11<1297::AID -JOC86>3.0.CO;2-T.

Kahn, B. H., and Coauthors, 2014: The Atmospheric Infrared Sounder version 6 cloud products. Atmos. Chem. Phys., 14, 399-426, doi:10.5194 /acp-14-399-2014.

Kapsch, M. L., R. G. Graversen, and M. Tjernström, 2013: Springtime atmospheric energy transport and the control of Arctic summer sea-ice extent. Nat. Climate Change, 3, 744-748, doi:10.1038 /nclimate1884.

Kay, J. E., and A. Gettelman, 2009: Cloud influence on and response to seasonal Arctic sea ice loss. J. Geophys. Res., 114, D18204, doi:10.1029/2009JD011773.

_- and T. L'Ecuyer, 2013: Observational constraints on Arctic Ocean clouds and radiative fluxes during the early 21st century. J. Geophys. Res. Atmos., 118, 7219-7236, doi:10.1002/jgrd.50489.

— - _ A. Gettelman, G. Stephens, and C. O'Dell, 2008: The contribution of cloud and radiation anomalies to the 2007 Arctic sea ice extent minimum. Geophys. Res. Lett., 35, L08503, doi:10.1029 /2008GL033451.

Kwok, R., and D. A. Rothrock, 2009: Decline in Arctic sea ice thickness from submarine and ICESat records: 1958-2008. Geophys. Res. Lett., 36, L15501, doi:10.1029/2009GL039035.

—, G. F. Cunningham, M. Wensnahan, I. Rigor, H. J. Zwally, and D. Yi, 2009: Thinning and volume loss of the Arctic Ocean sea ice cover: 2003-2008. J. Geophys. Res., 114, C07005, doi:10.1029/2009JC005312.

Law, K. S., and Coauthors, 2014: Arctic air pollution: New insights from POLARCAT-IPY. Bull. Amer. Meteor. Soc., 95, 1873-1895, doi:10.1175/BAMS -D-13-00017.1.

Liu, Y. and J. R. Key., 2014: Less winter cloud aids summer 2013 Arctic sea ice return from 2012 minimum. Environ. Res. Lett., 9, 044002, doi:10.1088/1748-9326/9/4/044002.

— J. J. Key, A. Schweiger, and J. Francis, 2006: Characteristics of satellite-derived clear-sky atmospheric temperature inversion strength in the Arctic, 1980-96. J. Climate, 19, 4902-4913, doi:10.1175 /JCLI3915.1.
— - - Z. Liu, X. Wang, and S. J. Vavrus, 2012: A cloudier Arctic expected with diminishing sea ice. Geophys. Res. Lett., 39, L05705, doi:10.1029/2012GL051251.

Lubin, D., and A. M. Vogelmann, 2006: A climatologically significant aerosol longwave indirect effect in the Arctic. Nature, 439, 453-456, doi:10.1038 /nature04449.

—, B. H. Kahn, M. A. Lazzara, P. Rowe, and V. P. Walden, 2015: Variability in AIRS-retrieved cloud amount and thermodynamic phase over west versus east Antarctica influenced by the SAM. Geophys. Res. Lett., 42, 1259-1267, doi:10.1002/2014GL062285.

Maslanik, J. A., C. Fowler, J. Stroeve, S. Drobot, J. Zwally, D. Yi, and W. Emery, 2007: A younger, thinner Arctic ice cover: Increased potential for rapid, extensive sea-ice loss. Geophys. Res. Lett., 34, L24501, doi:10.1029/2007GL032043.

- , J. Stroeve, C. Fowler, and W. Emery, 2011: Distribution and trends in Arctic sea ice age through spring 2011. Geophys. Res. Lett., 38, L13502, doi:10.1029/2011GL047735.

Medeiros, B., C. Deser, R. Tomas, and J. Kay, 2011: Arctic inversion strength in climate models. J. Climate, 24, 4733-4740, doi:10.1175/2011JCLI3968.1.

Morrison, H., G. de Boer, G. Feingold, J. Harrington, M. D. Shupe, and K. Sulia, 2012: Resilience of persistent Arctic mixed-phase clouds. Nat. Geosci., 5, 11-17, doi:10.1038/ngeo1332.

Mortin, J., S. E. L. Howell, L. Wang, C. Derksen, G. Svensson, R. G. Graversen, and T. M. Schrøder, 2014: Extending the QuikSCAT record of seasonal melt-freeze transitions over Arctic sea ice using ASCAT. Remote Sens. Environ., 141, 214-230, doi:10.1016/j.rse.2013.11.004.

Nygård, T., T. Valkonen, and T. Vihma, 2014: Characteristics of Arctic low-tropospheric humidity inversions based on radio soundings. Atmos. Chem. Phys., 14, 1959-1971, doi:10.5194/acp-14-1959-2014.

Pavelsky, T., J. Boé, A. Hall, and E. Fetzer, 2011: Atmospheric inversion strength over polar oceans in winter regulated by sea ice. Climate Dyn., 36, 945-955, doi:10.1007/s00382-010-0756-8.

Persson, P. O. G., 2012: Onset and end of the summer melt season over sea ice: Thermal structure and surface energy perspective from SHEBA. Climate Dyn., 39, 1349-1371, doi:10.1007/s00382-011-1196-9.

—, C. W. Fairall, E. L Andreas, P. S. Guest, and D. K. Perovich, 2002: Measurements near the Atmospheric Surface Flux Group tower at SHEBA: Near-surface conditions and surface energy budget. J. Geophys. Res., 107, 8045, doi:10.1029/2000JC000705.

Qiu, S., X. Dong, B. Xi, and J.-L. F. Li, 2015: Characterizing Arctic mixed-phase cloud structure and its 
relationship with humidity and temperature inversion using ARM NSA observations. J. Geophys. Res. Atmos., 120, 7737-7746, doi:10.1002/2014JD023022.

Schweiger, A. J., R. W. Lindsay, S. Vavrus, and J. A. Francis, 2008: Relationships between Arctic sea ice and clouds during autumn. J. Climate, 20, 4799-4810, doi:10.1175/2008JCLI2156.1.

Screen, J. A., C. Deser, I. Simmonds, and R. Tomas, 2014: Atmospheric impacts of Arctic sea-ice loss, 19792009: Separating forced change from atmospheric internal variability. Climate Dyn., 43, 333-344, doi:10.1007/s00382-013-1830-9.

Sedlar, J., 2014: Implications of limited liquid water path on static mixing within Arctic low-level clouds. J. Appl. Meteor. Climatol., 53, 2775-2789, doi:10.1175 /JAMC-D-14-0065.1.

— Inversion characterization during the Arctic melt season. Bound.-Layer Meteor., 132, 455-474, doi:10.1007/s10546-009-9407-1.

_ , and A. Devasthale, 2012: Clear-sky thermodynamic and radiative anomalies over a sea ice sensitive region of the Arctic. J. Geophys. Res., 117, D19111, doi:10.1029/2012JD017754.

—, M. D. Shupe, and M. Tjernström, 2012: On the relationship between thermodynamic structure and cloud top, and its climate significance in the Arctic. J. Climate, 25, 2374-2393, doi:10.1175 /JCLI-D-11-00186.1.

Serreze, M. C., and R. G. Barry, 2011: Processes and impacts of Arctic amplification: A research synthesis. Global Planet. Change, 77, 85-96, doi:10.1016/j .gloplacha.2011.03.004.

— , J. D. Kahl, and R. C. Schnell, 1992: Low-level temperature inversions of the Eurasian Arctic and comparisons with Soviet drifting stations. J. Climate, 5, 615-630, doi:10.1175/1520-0442(1992)005<0615:LL TIOT>2.0.CO;2.

Shupe, M. D., and J. M. Intrieri, 2004: Cloud radiative forcing of the Arctic surface: The influence of cloud properties, surface albedo, and solar zenith angle. J. Climate, 17, 616-628, doi:10.1175/1520-0442(2004)017<0616:CR FOTA $>2.0 . \mathrm{CO} ; 2$.

— , and Coauthors, 2008: A focus on mixed-phase clouds: The status of ground-based observational methods. Bull. Amer. Meteor. Soc., 89, 1549-1562, doi:10.1175/2008BAMS2378.1.

— , V. P. Walden, E. Eloranta, T. Uttal, J. R. Campbell, S. M. Starkweather, and M. Shiobara, 2011: Clouds at Arctic atmospheric observatories. Part I: Occurrence and macrophysical properties. J. Appl. Meteor. Climatol., 50, 626-644, doi:10.1175/2010JAMC2467.1.
—, P. O. G. Persson, I. M. Brooks, M. Tjernstrom, J. Sedlar, T. Mauritsen, S. Sjogren, and C. Leck, 2013: Cloud and boundary layer interactions over the Arctic sea ice in late summer. Atmos. Chem. Phys., 13, 9379-9400, doi:10.5194/acp-13-9379-2013.

Sotiropoulou, G., J. Sedlar, M. Tjernström, M. D. Shupe, I. M. Brooks, and P. O. G. Persson, 2014: The thermodynamic structure of summer Arctic stratocumulus and the dynamic coupling to the surface. Atmos. Chem. Phys., 14, 122573-122592, doi:10.5194 /acp-14-12573-2014.

Stroeve, J., M. Serreze, S. Drobot, S. Gearheard, M. Holland, J. Maslanik, W. Meier, and T. Scambos, 2008: Arctic sea ice extent plummets in 2007. Eos, Trans. Amer. Geophys. Union, 89, 13-14, doi:10.1029/2008EO020001.

Tjernström, M., and R. G. Graversen, 2009: The vertical structure of the lower Arctic troposphere analysed from observations and ERA-40 reanalysis. Quart. J. Roy. Meteor. Soc., 135, 431-433, doi:10.1002/qj.380.

—, C. Leck, P. O. G. Persson, M. L. Jensen, S. P. Oncley, and A. Targino, 2004: The summertime Arctic atmosphere: Meteorological measurements during the Arctic Ocean Experiment (AOE-2001). Bull. Amer. Meteor. Soc., 85, 1305-1321, doi:10.1175 /BAMS-85-9-1305.

—_, and Coauthors, 2005: Modeling the Arctic boundary layer: An evaluation of six ARCMIP regionalscale models with data from the SHEBA project. Bound.-Layer Meteor., 117, 337-381, doi:10.1007 /s10546-004-7954-z.

— the central Arctic summer during the Arctic Summer Cloud Ocean Study (ASCOS). Atmos. Chem. Phys., 12, 6863-6889, doi:10.5194/acp-12-6863-2012.

— , and Coauthors, 2014: The Arctic Summer Cloud Ocean Study (ASCOS): Overview and experimental design. Atmos. Chem. Phys., 14, 2823-2869, doi:10.5194/acp-14-2823-2014.

Uttal, T., and Coauthors, 2002: Surface Heat Budget of the Arctic Ocean. Bull. Amer. Meteor. Soc., 83, 255-276, doi:10.1175/1520-0477(2002)083<0255:SH BOTA $>2.3 . \mathrm{CO} ; 2$.

Vihma, T., 2014: Effects of Arctic sea ice decline on weather and climate: A review. Surv. Geophys., 35, 1175-1214, doi:10.1007/s10712-014-9284-0.

—, T. Kilpeläinen, M. Manninen, A. Sjöblom, E. Jakobson, T. Palo, J. Jaagus, and M. Maturilli, 2011: Characteristics of temperature and humidity inversions and low-level jets over Svalbard fjords in spring. Adv. Meteor., 2011, 486807, doi:10.1155/2011 1486807.

- , and Coauthors, 2014: Advances in understanding and parameterization of small-scale physical 
processes in the marine Arctic climate system: A review. Atmos. Chem. Phys., 14, 9403-9450, doi:10.5194 /acp-14-9403-2014.

Vowinkel, E., and S. Orvig, 1970: The climate of the North Polar Basin. Climates of the Polar Regions, S. Orvig, Ed., World Survey of Climatology, Vol. 14, Elsevier, 129-226.

Walsh, J. E., and W. L. Chapman, 1998: Arctic cloudradiation-temperature associations in observational data and atmospheric reanalyses. J. Climate, 11, 30303045, doi:10.1175/1520-0442(1998)011<3030:ACRTA $\mathrm{I}>2.0 . \mathrm{CO} ; 2$.

Wexler, H., 1936: Cooling in the lower atmosphere and the structure of polar continental air. Mon. Wea. Rev., 64, 122-136, doi:10.1175/1520-0493(1936)64<122:CI TLAA $>2.0 . C O ; 2$.

Wong, S., E. J. Fetzer, M. Schreier, G. Manipon, E. F. Fishbein, B. H. Kahn, Q. Yue, and F. W. Irion, 2015: Cloud-induced uncertainties in AIRS and ECMWF temperature and specific humidity. J. Geophys. Res. Atmos., 120, 1880-1901, doi:10.1002/2014JD022440. Woods, C., R. Caballero, and G. Svensson, 2013: Largescale circulation associated with moisture intrusions into the Arctic during winter. Geophys. Res. Lett., 40, 4717-4721, doi:10.1002/grl.50912.

Yue, Q., B. H. Kahn, E. J. Fetzer, and J. Teixeira, 2011: Relationship between marine boundary layer clouds and lower tropospheric stability observed by AIRS, CloudSat, and CALIOP. J. Geophys. Res., 116, D18212, doi:10.1029/2011JD016136.

Zhang, Y., and D. J. Seidel, 2011: Challenges in estimating trends in Arctic surface-based inversions from radiosonde data. Geophys. Res. Lett., 38, L17806, doi:10.1029/2011GL048728.

— - - J.-C. Golaz, C. Deser, and R. A. Tomas, 2011: Climatological characteristics of Arctic and Antarctic surface-based inversions. J. Climate, 24, 5167-5186, doi:10.1175/2011JCLI4004.1.

\section{NEW! PRINT \& CD FORMATS}

"Professor Lackmann has prepared an excellent synthesis of quintessential modern midlatitude synoptic-dynamic meteorology."

- LANCE BOSART, Distinguished Professor, Department of Atmospheric and Environmental Sciences, The University of Albany, State University of New York

\section{Midlatitude Synoptic Meteorology: Dynamics, Analysis, and Forecasting GARY LACKMANN}

The past decade has been characterized by remarkable advances in meteorological observation, computing techniques, and datavisualization technology. Midlatitude Synoptic Meteorologylinks theoretical concepts to modern technology and facilitates the meaningful application of concepts, theories, and techniques using real data. As such, it both serves those planning careers in meteorological research and weather prediction and provides

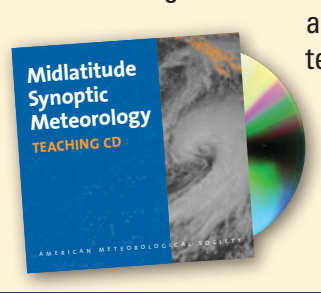
a template for the application of modern technology in the classroom.

Instructors: Midlatitude Synoptic Teaching CD, containing over 1,000 lecture slides, is now available!

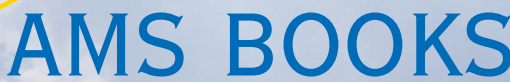

RESEARCH APPLICATIONS HISTORY www.ametsoc.org/amsbookstore 617-226-3998 


\section{AMS Members}

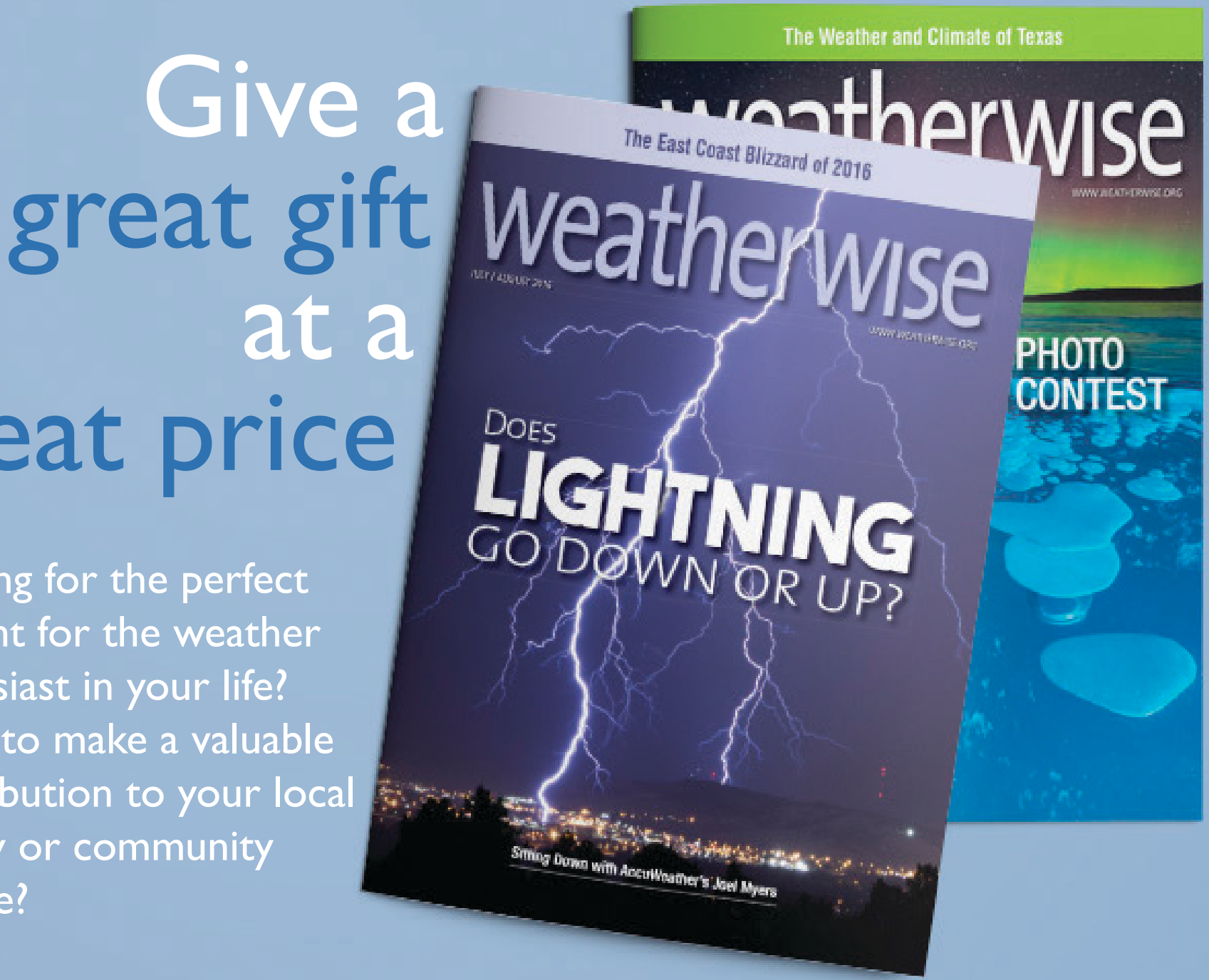

Send a subscription to Weatherwise magazine for just \$24.95*_That's nearly $50 \%$ off the list price!

Contact Member Services by e-mail at amsmem@ametsoc.org or by phone at 617-227-2425 to place all of your Weatherwise orders today!
Written for a general audience, Weatherwise offers a colorful and nontechnical look at recent discoveries in meteorology and climatology.

Check out the latest table of contents at www.weatherwise.org.

\section{Want your own?}

Then order a personal subscription at the same great price. 


\section{AMS BOOKS}

AMS MEMBERS GET FREE

\section{RESEARCH APPLICATIONS HISTORY}

\section{CLIMATE}

\section{The Thinking Person's Guide to Climate Change}

\section{ROBERT HENSON}

This fully updated and expanded revision of The Rough Guide to Climate Change combines years of data with recent research. It is the most comprehensive overview of climate science, acknowledging controversies but standing strong in its stance that the climate is changing-and something needs to be done.

(c) 2014, PAPERBACK, 520 PAGES, ISBN: 978-1-935704-73-7 LIST $\$ 30$ MEMBER $\$ 20$

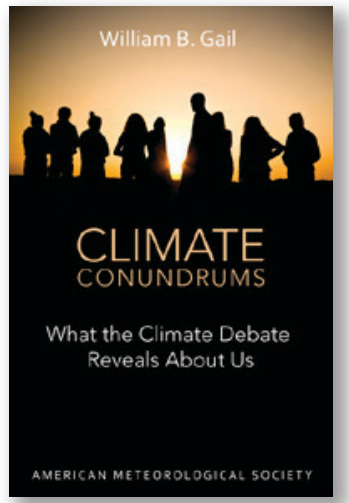

\section{Climate Conundrums:} What the Climate Debate Reveals about Us

WILLIAM B. GAIL

This is a journey through how we think, individually and collectively, about humanity's relationship with nature and more. Can we make nature better? Could science and religion reconcile? Gail's insights on such issues help us better understand who we are and find a way forward.

(c) 2014, PAPERBACK, 240 PAGES, ISBN: 978-1-935704-74-4 LIST \$30 MEMBER \$20

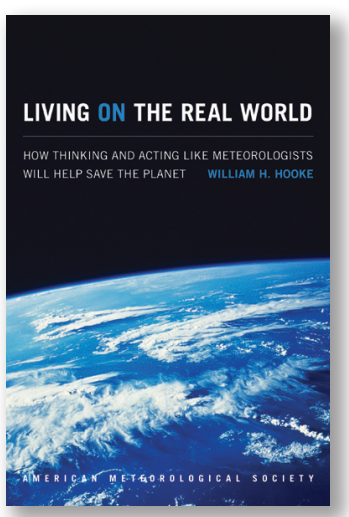

\section{Living on the Real World:} How Thinking and Acting Like Meteorologists Will Help Save the Planet WILLIAM H. HOOKE

Meteorologists focus on small bits of information while using frequent collaboration to make decisions. With climate change a reality, William $\mathrm{H}$. Hooke suggests we look to the way meteorologists operate as a model for how we can solve the 21st century's most urgent environmental problems.

GUIDES

\section{An Observer's Guide to Clouds} and Weather:

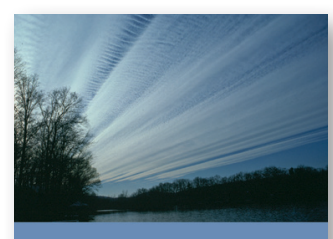

A Northeastern

Primer on Prediction

TOBY CARLSON, PAUL KNIGHT, AND CELIA WYCKOFF

AN OBSERVER'S GUIDE

CLOUDS AND WEATHER

A NORTHEASTERN PRIMER ON PREDICTION

WERIOAN METEOROLOCIOAL SOCIET

With help from Penn State experts, start at the beginning and go deep. This primer, intended for both serious enthusiasts and new meteorology students, will leave you with both refined observation skills and an understanding of the complex science behind the weather: the ingredients for making reliable predictions of your own. It connects fundamental meteorological concepts with the processes that shape weather patterns, and will make an expert of any dedicated reader.

(c) 2014, PAPERBACK, 210 PAGES,

ISBN: 978-1-935704-58-4 LIST \$30 MEMBER \$20

\section{Eloquent Science:}

A Practical Guide to Becoming a Better Writer, Speaker, and Atmospheric Scientist DAVID M. SCHULTZ

The ultimate communications manual for undergraduate and graduate students as well as researchers in the atmospheric sciences and their intersecting disciplines.

(c) 2009, PAPERBACK, 440 PAGES, ISBN 978-1-878220-91-2

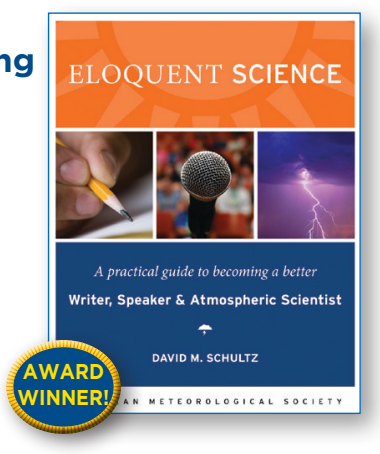

LIST \$45 MEMBER \$30

TEXTBOOK

\section{Midlatitude Synoptic Meteorology: Dynamics, Analysis, and Forecasting \\ GARY LACKMANN}

This textbook links theoretical concepts to modern technology, facilitating meaningful application of concepts, theories, and techniques using real data.

(C2011, PAPERBACK, 360 PAGES, ISBN 978-1-878220-10-3 LIST \$100 MEMBER \$75 STUDENT MEMB. \$65

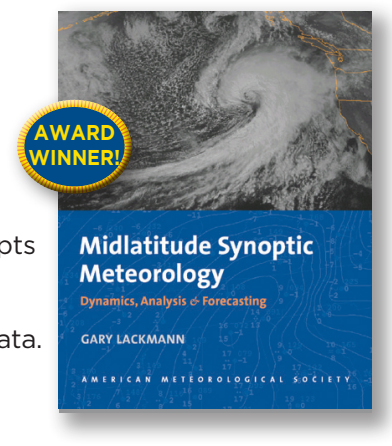

Midlatitude Synoptic Meteorology Teaching CD More than 1,000 PowerPoint Slides.

(c) 2013, CD, ISBN 978-1-878220-27-1 LIST \$100 MEMBER \$75 


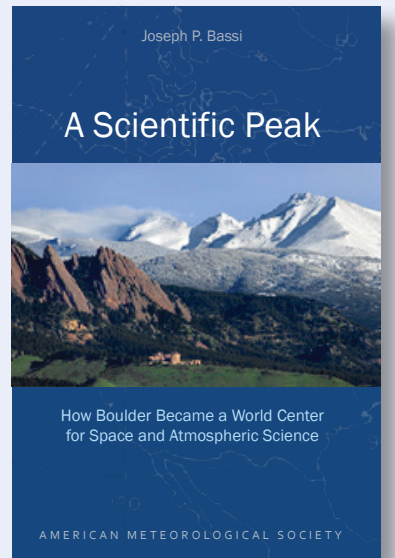

\section{A Scientific Peak:}

How Boulder Became a World Center for Space and Atmospheric Science

JOSEPH P. BASSI

How did big science come to Boulder, Colorado? Joe Bassi introduces us to the characters, including Harvard sun-Earth researcher Walter Orr Roberts, and the unexpected brew of politics, passion, and sheer luck that during the Cold War era transformed this "Scientific Siberia" to home of NCAR and NOAA.

(c) 2015, PAPERBACK, 264 PAGES, ISBN: 978-1-935704-85-0

LIST PRICE: $\$ 35.00$ MEMBER PRICE: $\$ 25.00$

METEOROLOGICAL MONOGRAPH SERIES

AMS Meteorological Monographs Vols. 1-55 (1947-2010) are available via Springer at springer.com/ams, with select volumes available in print via AMS at bookstore.ametsoc.org. Starting in 2016 with Vol. 56, new monographs will be open access, available via the AMS Journals Online site.

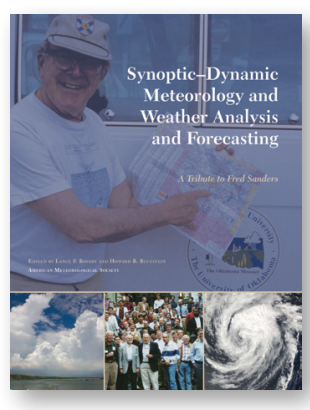

Synoptic-Dynamic Meteorology and Weather Analysis and Forecasting:

A Tribute to

Fred Sanders

EDITED BY LANCE F.

BOSART AND
HOWARD B. BLUESTEIN

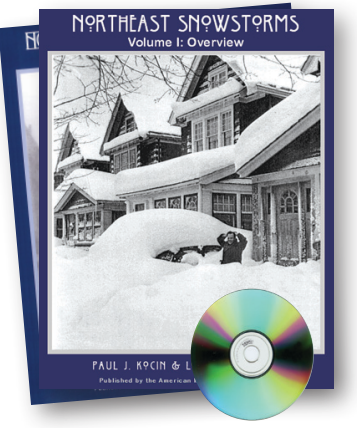

\section{Northeast} Snowstorms (Volume I: Overview, Volume II: The Cases) PAUL J. KOCIN AND LOUIS W. UCCELLINI

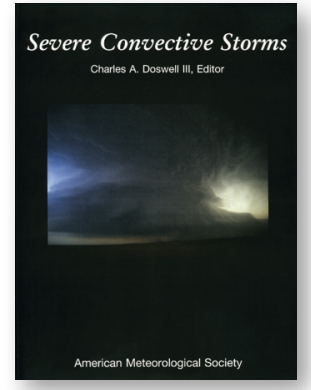

\section{Severe} Convective Storms

EDITED BY CHARLES A. DOSWELL III
HISTORY

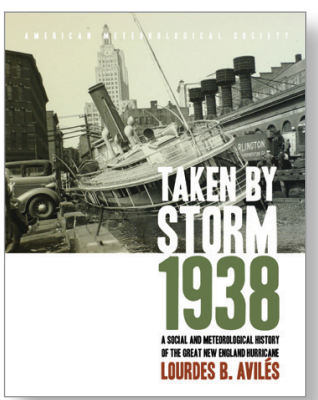

\section{Taken by} Storm, 1938:

A Social and Meteorological History of the Great New England Hurricane LOURDES B. AVILÉS

The science behind the 1938 Hurricane, which hit New England unannounced, is presented here for the first time along with new data that sheds light on the motivations of the Weather Bureau forecasters. This compelling history successfully weaves science, historical accounts, and social analyses to create a comprehensive picture of the most powerful and devastating hurricane to hit New England to date.

(c) 2013, HARDCOVER, 288 PAGES, ISBN: 978-1-878220-37-0 LIST \$40 MEMBER \$30

\section{Father Benito Viñes:}

The 19th-Century Life

and Contributions of a Cuban Hurricane Observer and Scientist

\section{LUIS E. RAMOS GUADALUPE} TRANSLATED BY OSWALDO GARCIA

Before Doppler radar and weather broadcasts, Spanish Jesuit Benito Viñes (1837-1893) spent decades observing the skies at Belen Observatory in colonial Cuba. Nicknamed "the Hurricane Priest," Viñes taught the public about the weather and developed the first network of weather observation stations in the Caribbean, groundwork for the hurricane warning systems we use today

(c) 2014, PAPERBACK, 172 PAGES

ISBN: 978-1-935704-62-1 LIST \$20 MEMBER \$16

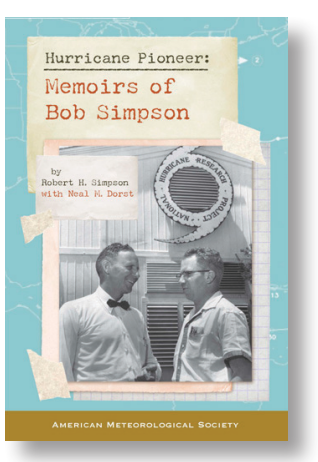

\section{Hurricane Pioneer:} Memoirs of Bob Simpson ROBERT H. SIMPSON AND NEAL DORST

In 1951, Bob Simpson rode a plane into a hurricane-just one of the many pioneering exploits you'll find in these memoirs. Bob and his wife Joanne are meteorological icons: Bob was the first director of the National Hurricane Research Project and a director of the National Hurricane Center. He helped to create the Saffir-Simpson Hurricane Scale; the public knows well his Categories 1-5. Proceeds from this book help support the AMS's K. Vic Ooyama Scholarship Fund.

(c) 2015, PAPERBACK, 156 PAGES

ISBN: 978-1-935704-75-1 LIST \$25 MEMBER \$20 


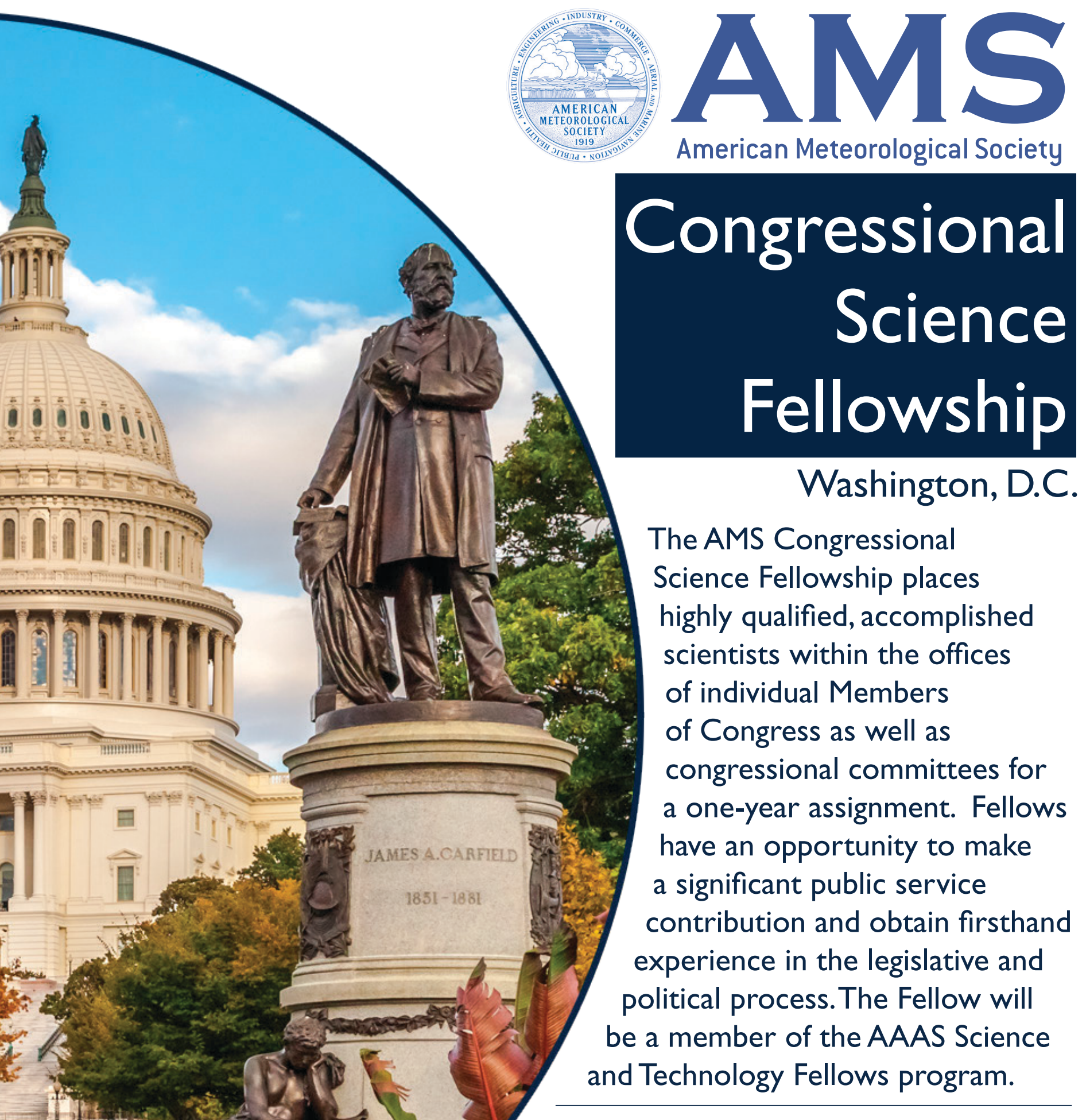

Fellowship Term: September I, $2017-$ August 31, 2018

Eligibility

- Ph.D. or equivalent in atmospheric or related sciences

- Member of AMS

- U.S. citizen (federal employees not eligible)

Visit www.ametsoc.org/csf and apply now!

Deadline: February I, 2017 